\title{
P2Y 12 Receptors in Spinal Microglia Are Required for Neuropathic Pain after Peripheral Nerve Injury
}

\author{
Hidetoshi Tozaki-Saitoh, ${ }^{1}$ Makoto Tsuda, ${ }^{1}$ Hiroyuki Miyata, ${ }^{1}$ Kazuaki Ueda, ${ }^{1}$ Shinichi Kohsaka, ${ }^{2}$ and Kazuhide Inoue ${ }^{1}$ \\ ${ }^{1}$ Department of Molecular and System Pharmacology, Graduate School of Pharmaceutical Sciences, Kyushu University, Higashi, Fukuoka 812-8582, Japan, \\ and ${ }^{2}$ Department of Neurochemistry, National Institute of Neuroscience, Kodaira, Tokyo 187-8502, Japan
}

\begin{abstract}
Extracellular nucleotides have been implicated as signaling molecules used by microglia to sense adverse physiological conditions, such as neuronal damage. They act through purinoceptors, especially the G-protein-coupled P2Y receptor P2Y ${ }_{12} \mathrm{R}$. Emerging evidence has indicated that activated spinal microglia responding to nerve injury are key cellular intermediaries in the resulting highly debilitating chronic pain state, namely neuropathic pain. However, the role of microglial $\mathrm{P} 2 \mathrm{Y}_{12} \mathrm{Rs}$ in neuropathic pain remains unknown. Here, we show that the level of $\mathrm{P}_{2} \mathrm{Y}_{12} \mathrm{R}$ mRNA expression was markedly increased in the spinal cord ipsilateral to the nerve injury and that this expression was highly restricted to ionized binding calcium adapter molecule 1-positive microglia. An increase in the immunofluorescence of $\mathrm{P} 2 \mathrm{Y}_{12} \mathrm{R}$ protein in the ipsilateral spinal cord was also observed after nerve injury, and $\mathrm{P} 2 \mathrm{Y}_{12} \mathrm{R}$-positive cells were double labeled with the microglial marker OX-42. Blocking spinal $\mathrm{P} 2 \mathrm{Y}_{12} \mathrm{R}$ by the intrathecal administration of its antagonist AR-C69931MX prevented the development of tactile allodynia (pain hypersensitivity to innocuous stimuli), a hallmark of neuropathic pain syndrome. Furthermore, mice lacking $P 2 r y_{12}\left(P 2 r y_{12}{ }^{-/}\right)$displayed impaired tactile allodynia after nerve injury without any change in basal mechanical sensitivity. Moreover, a single intrathecal administration of AR-C69931MX or oral administration of clopidogrel (a P2 ${ }_{12} \mathrm{R}$ blocker clinically in use) to nerve-injured rats produced a striking alleviation of existing tactile allodynia. Together, our findings indicate that activation of $\mathrm{P} 2 \mathrm{Y}_{12} \mathrm{Rs}$ in spinal microglia may be a critical event in the pathogenesis of neuropathic pain and suggest that blocking microglial $\mathrm{P} 2 \mathrm{Y}_{12} \mathrm{R}$ might be a viable therapeutic strategy for treating neuropathic pain.
\end{abstract}

Key words: $\mathrm{P}_{2} \mathrm{Y}_{12}$ receptor; microglia; neuropathic pain; purinergic; spinal cord; analgesia

\section{Introduction}

Peripheral nerve injury leads to a persistent neuropathic pain state in which innocuous stimulation elicits pain behavior (tactile allodynia). Recent studies have revealed that microglia, the immune effector cells in the CNS, critically contribute to the pathogenesis of neuropathic pain (Watkins and Maier, 2003; Marchand et al., 2005; Tsuda et al., 2005). Therefore, glial cells, especially microglia, have received much attention as a new therapeutic target for the treatment of neuropathic pain.

Extracellular nucleotides are known to be potent stimulators of microglia (Inoue, 2006); they play roles in various physiological and pathophysiological functions by activating purinergic receptors, which are classified into the ionotropic $\mathrm{P} 2 \mathrm{X}$ receptors (P2XR) and the metabotropic P2Y receptors (P2YR) (Burnstock, 2006). Microglia predominantly express $P 2 X_{4} R, P 2 X_{7} R, P 2 Y_{6} R$, and $\mathrm{P} 2 \mathrm{Y}_{12} \mathrm{R}$ purinoceptors (Koizumi et al., 2007). We have shown previously that activation of $\mathrm{P} 2 \mathrm{X}_{4} \mathrm{R}$, which is upregulated

Received Sept. 13, 2007; revised March 13, 2008; accepted March 31, 2008.

This work was supported by grants from the Ministry of Education, Culture, Sports, Science, and Technology of Japan (H.S.-T., M.T., K.I.). We are grateful to Dr. Kazuo Umemura for providing P2ry12 knock-out mice and to Dr. David Julius for providing polyclonal anti-P2Y ${ }_{12}$ antibody.

Correspondence should be addressed to Dr. Kazuhide Inoue, Department of Molecular and System Pharmacology, Graduate School of Pharmaceutical Sciences, Kyushu University, 3-1-1 Maidashi, Higashi, Fukuoka 812-8582, Japan. E-mail: inoue@phar.kyushu-u.ac.jp.

DOl:10.1523/JNEUROSCI.0323-08.2008

Copyright $\odot 2008$ Society for Neuroscience $\quad$ 0270-6474/08/284949-08\$15.00/0 in spinal microglia after peripheral nerve injury, contributes to neuropathic pain through a release of brain-derived neurotrophic factor (Tsuda et al., 2003; Coull et al., 2005). Our recent study revealed that activating $\mathrm{P}_{2} \mathrm{Y}_{6} \mathrm{Rs}$ induces phagocytosis of brain microglia through the $\mathrm{G}_{\mathrm{q}} /$ phospholipase $\mathrm{C} / \mathrm{IP}_{3}$ pathway (Koizumi et al., 2007). Furthermore, $\mathrm{P} 2 \mathrm{Y}_{12} \mathrm{R}$, which is coupled to $\mathrm{G}_{\mathrm{i}}$ signaling in microglia, is implicated in ATP-induced membrane ruffling and chemotaxis toward a source of ATP (Honda et al., 2001; Haynes et al., 2006; Ohsawa et al., 2007). A recent study has demonstrated that $\mathrm{P} 2 \mathrm{Y}_{12} \mathrm{R}$ is required for the extension of microglial processes to engulf injured cells in vivo (Davalos et al., 2005; Haynes et al., 2006; Kurpius et al., 2007). Moreover, whereas the microglial ATP receptors (for example, $\mathrm{P} 2 \mathrm{X}_{4} \mathrm{R}$, $\mathrm{P} 2 \mathrm{X}_{7} \mathrm{R}$, and $\mathrm{P} 2 \mathrm{Y}_{6} \mathrm{R}$ ) are expressed in both microglia and peripheral macrophages (Di Virgilio et al., 2001), the $\mathrm{P} 2 \mathrm{Y}_{12} \mathrm{R}$ subtype is unique in that its expression is restricted to microglia in CNS parenchyma (Sasaki et al., 2003; Haynes et al., 2006). These observations suggest that microglia are key sensors of adverse conditions in the CNS, detecting nucleotides via P2 ${ }_{12}$ Rs. Despite rapid progress in elucidating the physiological functions of microglia mediated by $\mathrm{P} 2 \mathrm{Y}_{12} \mathrm{R}$, relatively little insight has been gained concerning the in vivo role of $\mathrm{P}_{2} \mathrm{Y}_{12} \mathrm{Rs}$ in pathophysiological conditions in the CNS.

In the present study, we sought to investigate the role of microglial P2 $\mathrm{Y}_{12}$ Rs in the spinal cord in neuropathic pain and discovered that activation of $\mathrm{P} 2 \mathrm{Y}_{12} \mathrm{Rs}$ in spinal microglia is a critical 
step in the pathogenesis of neuropathic pain, using selective antagonists for $\mathrm{P} 2 \mathrm{Y}_{12} \mathrm{R}$ and mice lacking $\mathrm{P} 2 \mathrm{Y}_{12} \mathrm{R}$. Our present data suggest that blocking microglial $\mathrm{P}_{2} \mathrm{Y}_{12} \mathrm{Rs}$ might be a viable therapeutic strategy for treating neuropathic pain.

\section{Materials and Methods}

All experimental procedures were performed under the guidelines of Kyushu University.

Animals. Male Wistar rats (Japan SLC, Hamamatsu, Japan) and 10week-old wild-type and $\mathrm{P} 2 \mathrm{ry}_{12}{ }^{-/-}$mice, both of which were derived from C57BL/6J × 129S1 mice (Hashimoto et al., 2007) and were kindly provided by Dr. Kazuo Umemura (Hamamatsu University School of Medicine, Hamamatsu, Japan), were used in this study. Animals were housed with a $12 \mathrm{~h} \mathrm{light/dark} \mathrm{cycle} \mathrm{(lights} \mathrm{on} \mathrm{at} \mathrm{8:00} \mathrm{A.M.,} \mathrm{lights} \mathrm{off} \mathrm{at}$ 8:00 P.M.) at a constant room temperature of $23 \pm 2^{\circ} \mathrm{C}$ and humidity of $45-65 \%$.

Neuropathic pain model. The left L5 spinal nerve of rats was tightly ligated with silk and cut just distal to the ligature under isoflurane (2\%) anesthesia. For the experiments using mice, the left L5 spinal nerve was transected. To assess the tactile allodynia, calibrated von Frey filaments (0.4-15 g for rats, $0.02-2.0 \mathrm{~g}$ for mice; North Coast Medical, Morgan Hill, CA) were applied to the plantar surface of the hindpaw. The $50 \%$ paw-withdrawal threshold (PWT) was determined by the up-down method (Chaplan et al., 1994).

Real-time reverse transcription-PCR. Rats were deeply anesthetized with pentobarbital, perfused transcardially with PBS, and the L5 spinal cord was removed immediately. The tissues were vertically separated by median, and hemisections of the spinal cord were subjected to total RNA extraction using Trisure (Bioline, Danwon-Gu, South Korea) according to the protocol of the manufacturer and purified with RNeasy mini plus kit (Qiagen, Valencia, CA). The amount of total RNA was quantified by measuring $\mathrm{OD}_{260}$ using a Nanodrop spectrophotometer (Nanodrop, Wilmington, DE). For reverse transcription with random 6-mer primers, $400 \mathrm{ng}$ of total RNA was transferred to the reaction with Prime Script reverse transcriptase (Takara, Kyoto, Japan). Quantitative PCR was performed with Premix Ex Taq (Takara) using a 7500 real-time PCR system (Applied Biosystems, Foster City, CA) according to protocol of the manufacturer, and the data were analyzed by 7500 System SDS Software 1.3.1 (Applied Biosystems) using the standard curve method. Expression levels were normalized to the values for glyceraldehyde-3-phosphate dehydrogenase (GAPDH). The TaqMan probe for $\mathrm{P}^{2} \mathrm{RY}_{12}$ (5'-FAMCACCAGACCATTTAAAACTTCCAGCCCC-TAMRA-3'), the forward primer for P2RY 12 (5'-TAACCATTGACCGATACCTGAAGA-3'), and the reverse primer for P2RY 12 (5'-TTCGCACCCAAAAGATTGC- $\left.3^{\prime}\right)$, as well as the primers and probe for GAPDH, were obtained from Applied Biosystems.

In situ hybridization. Digoxigenin (DIG)-labeled RNA probes were designed having complementary sequence of rat P2ry 12 mRNA (GenBank accession number NM_022800) positioned at 26-616 bases. Animals were anesthetized and perfused transcardially with $4 \%$ paraformaldehyde/PBS, pH 7.4, $7 \mathrm{~d}$ after nerve injury. The L5 spinal cord was removed and again fixed with Tissue Fixative (Genostaff, Tokyo, Japan). Paraffin-embedded tissues $(6 \mu \mathrm{m})$ were dewaxed with xylene and rehydrated. After proteinase $\mathrm{K}$ treatment $\left(7 \mathrm{mg} / \mathrm{ml}, 30 \mathrm{~min}, 37^{\circ} \mathrm{C}\right)$ and acetylation by acetic anhydride $(0.25 \%)$, hybridization was performed with probes at concentrations of $300 \mathrm{ng} / \mathrm{ml}$ at $60^{\circ} \mathrm{C}$ for $16 \mathrm{~h}$. After hybridization, a series of washing was performed, followed by RNase treatment ( 50 $\mathrm{mg} / \mathrm{ml}, 30 \mathrm{~min}, 37^{\circ} \mathrm{C}$ ). The sections were blocked with $0.5 \%$ blocking reagent (Roche, Indianapolis, IN) in Tris-buffered saline containing Tween 20 and incubated with anti-DIG alkaline phosphatase conjugate (1:1000; Roche) for $2 \mathrm{~h}$ at room temperature. Coloring reactions were performed with nitro blue tetrazolium chloride/5-bromo-4-chloro-3indolyl phosphate solution (NBT/BCIP) (Sigma, St. Louis, MO) overnight. The sections were counterstained with Kernechtrot stain solution (Mutoh, Tokyo, Japan) and then mounted with Crystal/Mount (BioMeda, Foster City, CA). For immunohistochemistry as a second staining after NBT/BCIP treatment, the sections were treated $0.3 \%$ hydrogen peroxide and Protein Block (Dako, High Wycombe, UK) for 10 min and then incubated with the anti-ionized binding calcium adapter molecule 1 (Iba1) rabbit polyclonal antibody $(0.1 \mu \mathrm{g} / \mathrm{ml}$; Wako Pure Chemicals, Osaka, Japan) at $4^{\circ} \mathrm{C}$ overnight. The sections were treated with Histofine Simplestain rat MAX-PO (MULTI) (Nichirei, Tokyo, Japan) for $30 \mathrm{~min}$, incubated with $\mathrm{DAB}$, and then counterstained with Kernechtrot stain solution. Colocalization was assessed in 12 nonoverlapping regions of the spinal cord (88 cells in total).

Immunohistochemistry. Animals were anesthetized and perfused transcardially with $4 \%$ paraformaldehyde/PBS, $\mathrm{pH} 7.4$, on day 14 after nerve injury. The L5 spinal cord was removed and postfixed at $4^{\circ} \mathrm{C}$ for $5 \mathrm{~h}$ and then transferred to $30 \%$ sucrose/PBS for $24 \mathrm{~h}$. Floating transverse sections $(30 \mu \mathrm{m})$ were blocked in solution containing $3 \%$ normal goat serum and $0.1 \%$ Triton $\mathrm{X}-100$ for $3 \mathrm{~h}$ at room temperature. Then, the sections were incubated $48 \mathrm{~h}$ at $4^{\circ} \mathrm{C}$ with primary antibodies against $\mathrm{P} 2 \mathrm{Y}_{12} \mathrm{R}$ (rabbit polyclonal anti-P2 $\mathrm{Y}_{12} \mathrm{R}, 1: 500$; kindly provided by Dr. David Julius, University of California, San Francisco, San Francisco, CA), OX-42 (rat or mouse monoclonal anti-OX-42, 1:2000; Serotec, Oxford, UK), Iba1 (rabbit polyclonal anti-Iba1, 1:2000; Wako Pure Chemicals), glial fibrillary acidic protein (GFAP) (mouse monoclonal anti-GFAP, 1:1000; Millipore Bioscience Research Reagents, Temecula, CA), and microtubule-associated protein-2 (MAP2) (mouse monoclonal antiMAP2, 1:500; Millipore Bioscience Research Reagents). After washing, the sections were then incubated with fluorescent-conjugated secondary antibody (Alexa 488 and Alexa 543, 1:1000; Invitrogen, Carlsbad, CA) for $3 \mathrm{~h}$ at room temperature. The sections were mounted with Vectashield (Vector Laboratories, Burlingame, CA). Fluorescent images were obtained with a confocal microscope (LSM 5 Pascal; Carl Zeiss, Jena, Germany) and analyzed with Zeiss LSM Image Brower (Carl Zeiss).

Drug administration. For intrathecal drug administration, under isoflurane $(2 \%)$ anesthesia, rats were implanted with a 32-gauge intrathecal catheter (ReCathCo, Allison Park, PA) in the lumbar enlargement (close to L4-L5 segments) of the spinal cord (Tsuda et al., 2003). After $4 \mathrm{~d}$ recovery, the catheter placement was verified by the observation of transient hindpaw paralysis induced by intrathecal injection of lidocaine $(2 \%, 5 \mu \mathrm{l})$. Animals that failed to show any paralysis were not used in experiments. After peripheral nerve injury, rats were administered intrathecally PBS ( $5 \mu \mathrm{l}$, as a vehicle control) or AR-C69931MX (0.5, 5.0, and $50 \mathrm{nmol}$ in $5 \mu \mathrm{l}$ ) twice a day (9:00 A.M. and 7:00 P.M.) from day 0 (just after nerve injury) to day 7 . Measurement of PWT was performed just before evening drug administration (at least $9 \mathrm{~h}$ after the first of daily administration). To test the effects of AR-C69931MX (0.5, 5.0, and 50 $\mathrm{nmol}$ in $5 \mu \mathrm{l}$ of PBS), the orally active P2 $\mathrm{Y}_{12} \mathrm{R}$ antagonist (Emmons and Taylor, 2007) clopidogrel $(1,10$, and $25 \mathrm{mg} / \mathrm{kg}$, suspended in $0.5 \%$ calboxymethyl cellulose; LKT Laboratories, St. Paul, MN), MRS2211(500 pmol in $5 \mu \mathrm{l} \mathrm{PBS}$; Tocris Bioscience, Bristol, UK), and MRS2179 (50 pmol in $5 \mu$ l PBS; Sigma), on existing tactile allodynia, drugs were acutely administered intrathecally or orally to nerve-injured rats on day 7 after nerve injury. Drug administration was performed just after premeasurement, and PWT was measured at each time point.

Statistical analysis. All data are presented as means \pm SEM. The statistical significance of differences between the values was determined by paired $t$ tests or ANONVA with a post hoc test (Tukey's test). A $p$ value of $<0.05$ was considered to be statistically significant.

\section{Results}

\section{Upregulation of $\mathrm{P} 2 \mathrm{Y}_{12}$ receptor in the dorsal horn after} peripheral nerve injury

Using real-time PCR, we examined the level of $\mathrm{P} 2 \mathrm{Y}_{12} \mathrm{R}$ mRNA in total RNA extracts from the spinal cord ipsilateral and contralateral to an injury to the L5 spinal nerve. We found that the expression of $\mathrm{P} 2 \mathrm{Y}_{12} \mathrm{R}$ mRNA in the ipsilateral spinal cord was markedly increased after nerve injury $(p<0.05)$ (Fig. $1 A$ ). A significant increase was observed from day $3(3.23 \pm 0.48$-fold increase to uninjured spinal cord) after injury; $\mathrm{P} 2 \mathrm{Y}_{12} \mathrm{R}$ mRNA levels peaked on day 7 (3.92 \pm 0.69-fold) and decreased afterward. We also performed in situ hybridization and observed strong $\mathrm{P} 2 \mathrm{Y}_{12} \mathrm{R}$ mRNA signals dotted throughout the ipsilateral dorsal horn $7 \mathrm{~d}$ after nerve injury. The number of $\mathrm{P}_{2} \mathrm{Y}_{12} \mathrm{R}$ mRNA-positive cells in 

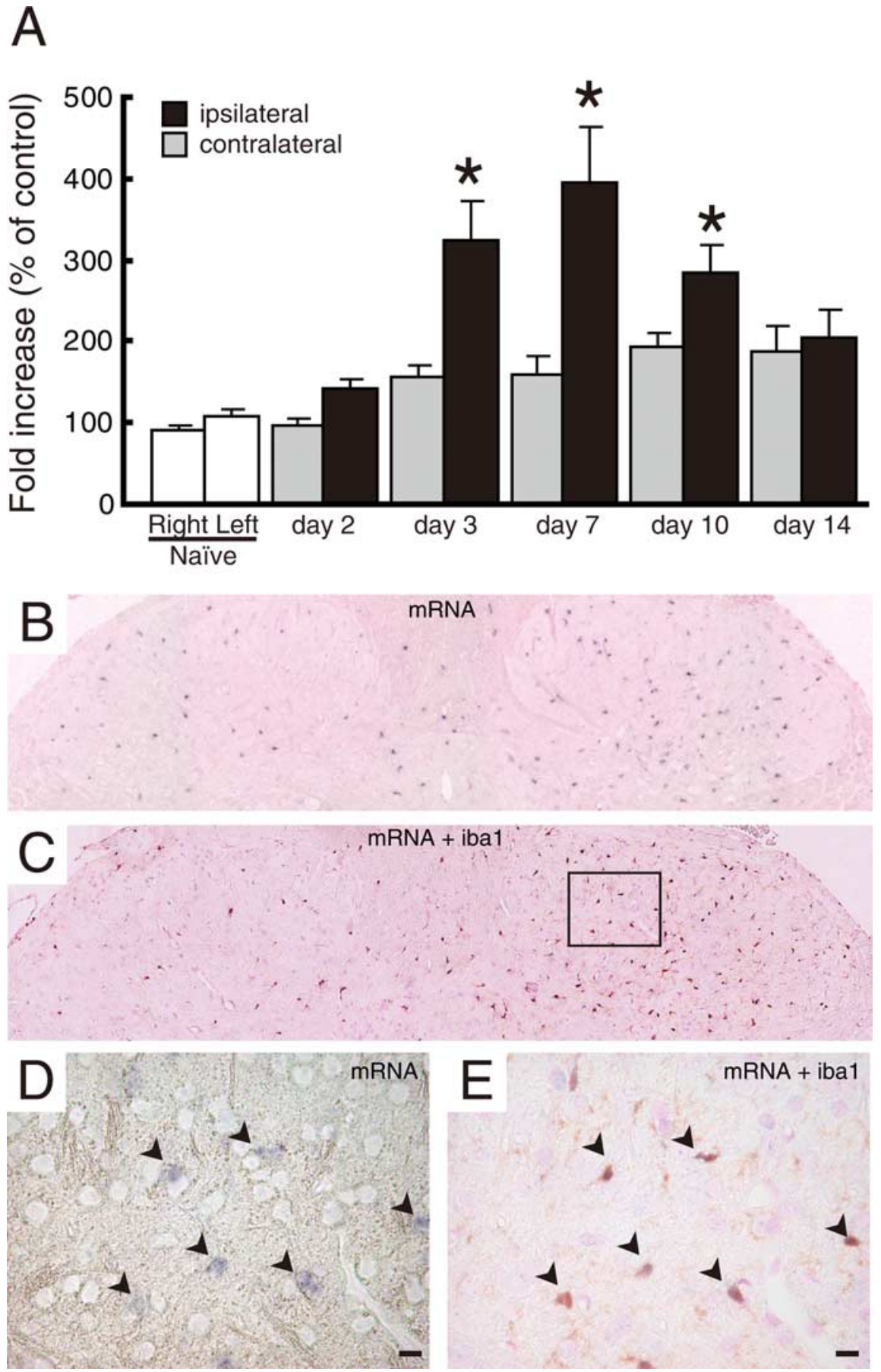

Figure 1. Upregulation of $P 2 Y_{12} R$ mRNA after peripheral nerve injury. Quantitative and histological analyses of $P 2 Y_{12} R m R N A$ expression in the spinal cord are shown. $A$, Total RNA extracted from rat spinal cord was subjected to quantitative analysis of $P 2 Y_{12}$ mRNA expression after peripheral nerve injury by real-time $P C R$. Bar graphs show the average fold increase in the level of $P 2 Y_{12}$ mRNA expression in spinal cord hemisections compared with the mean expression level of $P 2 Y_{12} m R N A$ in naive animals. Each measurement was normalized to GAPDH content. Data are means \pm SEM of five individual animals $\left({ }^{*} p<0.05\right.$ vs the naive spinal cord, one-way ANOVA post hoc Tukey's test). $\boldsymbol{B}$, A DIG-labeled RNA probe specific for P2Y $Y_{12}$ mRNA was visualized by in situ hybridization in rat spinal cord, $7 \mathrm{~d}$ after the nerve injury. C, An RNA-probed slice was subsequently stained with anti-lba1 antibody and visualized with $D A B$ staining. $\boldsymbol{D}, \boldsymbol{E}$, Magnifications of the squared area show the sections before and after lba1 staining. Arrowheads indicate colocalization of $\mathrm{P}_{2 \mathrm{Y}_{12}}$ mRNA-positive cells and lba1 signals. Scale bars, $10 \mu \mathrm{m}$. cells were labeled with Ibal ( $94.5 \pm 3.1 \%$ of $\mathrm{P}_{2} \mathrm{Y}_{12} \mathrm{R}$-positive cells) in both the ipsilateral and contralateral dorsal horns (Fig. $1 C-E)$. We also performed immunolabeling for $\mathrm{P}_{2} \mathrm{Y}_{12} \mathrm{R}$ using a specific antibody (Haynes et al., 2006) and found that the $\mathrm{P}_{2} \mathrm{Y}_{12} \mathrm{R}$ immunofluorescence was markedly enhanced in the ipsilateral dorsal horn on days 7 and 14 after nerve injury (Fig. $2 A-D)$. Using cell-type-specific markers (MAP2 to label neurons, GFAP to label astrocytes, and OX-42 to label microglia), we found that almost all of the $\mathrm{P} 2 \mathrm{Y}_{12} \mathrm{R}$ positive cells were double labeled with OX-42 (Fig. $2 E, F$ ) but not with the other markers (Fig. 2G-J). From these results, we conclude that, in the dorsal horn after nerve injury, the level of $\mathrm{P} 2 \mathrm{Y}_{12} \mathrm{R}$ expression is dramatically increased and that this expression is highly restricted to microglia. $\mathrm{P}_{2} \mathrm{Y}_{12} \mathrm{R}$ expression was not observed in neurons or astrocytes, although periphery platelets also expressed $\mathrm{P} 2 \mathrm{Y}_{12} \mathrm{R}$.

\section{Inhibition of tactile allodynia} development by blocking $\mathrm{P}_{2} \mathrm{Y}_{12} \mathrm{R}$ To investigate the role of $\mathrm{P}_{2} \mathrm{Y}_{12} \mathrm{Rs}$ expressed in spinal microglia in neuropathic pain, we intrathecally administered ARC69931MX, an antagonist for $\mathrm{P}_{2} \mathrm{Y}_{12} \mathrm{R}$ (Ingall et al., 1999), to rats twice a day for $7 \mathrm{~d}$, through a catheter whose tip was positioned near the $\mathrm{L} 4 / 5$ spinal cord. In vehicle (PBS)-treated rats, the PWT was decreased after injury to the L5 spinal nerve ( $p<$ $0.05)$ (Fig. 3A). In contrast, repeated intrathecal administration of AR-C69931MX markedly suppressed this decrease in PWT after nerve injury, in a dose-dependent manner $(p<0.05)$ (Fig. 3A). In rats that had received 50 pmol of AR-C69931MX, the PWT on every testing day was not significantly different from that before nerve injury. However, AR-C69931MX, at any dose we tested, did not affect PWT on the side contralateral to the nerve injury (Fig. $3 B)$. In addition, neither motor abnormality nor sedative effects were observed in PBS- or AR-C69931MX-treated rats throughout the experiments. These results indicate that AR-C69931MX prevents the development of tactile allodynia after peripheral nerve injury.

To examine whether AR-C69931MX affects activation of spinal microglia, we performed immunolabeling of spinal sections from AR-C69931MX-treated nerve-injured rats with the microglial the ipsilateral dorsal horn was $\sim 3.3$-fold higher than that in the contralateral side (Fig. $1 B$ ). To identify the cell type positive for P2 $\mathrm{Y}_{12} \mathrm{R}$ mRNA signals, we combined in situ hybridization for P2 $\mathrm{Y}_{12} \mathrm{R}$ mRNA with immunohistochemistry for Iba1, a marker of microglia, and found that almost all of $\mathrm{P}_{2} \mathrm{Y}_{12} \mathrm{R}$ mRNA-expressing marker OX-42. As reported previously (Tsuda et al., 2003), a marked increase in OX-42 immunoreactivity was observed in the ipsilateral dorsal spinal cords of vehicle-treated rats $7 \mathrm{~d}$ after nerve injury (Fig. $3 C, D$ ). In contrast to the effect of tactile allodynia, repeated intrathecal administration of AR- 
C69931MX (50 pmol) did not suppress this increase in OX-42 labeling (Fig. $3 E, F)$.

\section{P2ry ${ }_{12}$ deficiency attenuates} development of tactile allodynia

To clearly determine the functional relevance of $\mathrm{P} 2 \mathrm{Y}_{12} \mathrm{R}$ in neuropathic pain, we used $\mathrm{P} 2 \mathrm{Y}_{12} \mathrm{R}$-deficient mice $\left(\mathrm{P} 2 \mathrm{ry}_{12}{ }^{-/}\right.$ mice). $P 2 r y 12^{-/-}$mice showed no alteration in basal mechanical sensitivity compared with wild-type mice (wild-type, $1.64 \pm 0.17 \mathrm{~g} ;$ P $2 r y 12^{-/-}, 1.81 \pm 0.18 \mathrm{~g}$ ). In wild-type mice with an injury to the L5 spinal nerve, a progressive decrease in PWT was observed after nerve injury $(p<0.05)$ (Fig. $4 A$ ). In contrast, this decrease in PWT was not seen in $P 2 r y 12^{-1-}$ mice. A significant difference in PWT between P2ry $12^{-/-}$ mice and wild-type mice was observed from day 5 to day $14(p<0.05)$. However, the loss of P2ry12 did not change the PWT in the contralateral hindpaw after nerve injury (Fig. 4A) and did not result in a deficit in motor function. In addition, we confirmed that the level of $\mathrm{P} 2 \mathrm{Y}_{12}$ mRNA in the ipsilateral spinal cord was increased after injury in wild-type mice (data not shown), as observed in the rat spinal cord.

Because several studies have revealed that $\mathrm{P} 2 \mathrm{Y}_{12} \mathrm{Rs}$ on microglia contribute to their chemotaxis toward sites of injury, we performed immunohistochemical analysis to observe how the localization of spinal microglia is altered by P2ry 12 deficiency. Immunofluorescence for Iba1 in the dorsal horns of wild-type mice was enhanced in the ipsilateral dorsal horn compared with the contralateral dorsal horn, $14 \mathrm{~d}$ after nerve injury (Fig. $4 B, C$ ). In $P 2 r y 12^{-/-}$ mice, Ibal immunofluorescence was also increased in the ipsilateral side (Fig. 4D,E). In wild-type mice, the number of Iba1positive microglia in the dorsal horn was increased by $\sim 2.6 \pm 0.2$-fold compared with contralateral side $(181 \pm 41$ cells in the ipsilateral side, $68 \pm 7$ cells in the contralateral side). In contrast, the increase in P2ry $12^{-/-}$mice was $\sim 2.0 \pm 0.2$-fold (136 \pm 22 cells on the ipsilateral side, $69 \pm$ 8 cells on the contralateral side) increase to the contralateral side. Statistical analysis indicated a significant increase of microglial number in the ipsilateral dorsal horn in each genotypes, but in the ipsilateral dorsal horn between these two genotypes ( $p=0.11$ in comparisons between ipsilateral numbers, $p=0.09$ in comparisons between fold increases). Microglia in the ipsilateral dorsal horns of wild-type mice displayed hypertrophy in their somata and had short, thick processes (Fig. $4 F, G)$, which are known to be morphological features of activated microglia. Similar morphological changes in microglia were observed in the dorsal horn microglia of $P 2 r y 12^{-/-}$mice after nerve injury (Fig. $4 H, I)$.
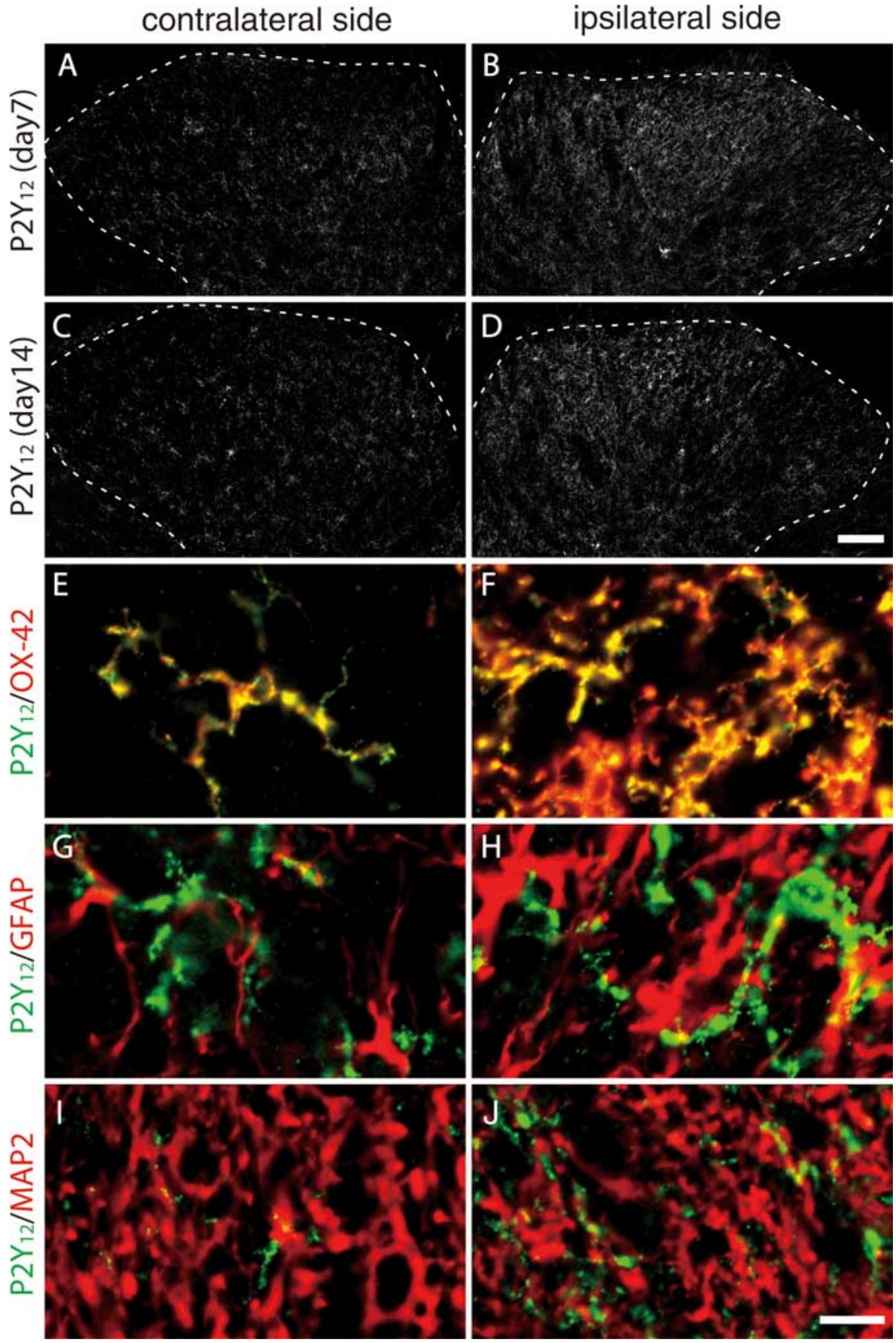

Figure 2. $P 2 Y_{12} R$ immunoreactivity localized to rat spinal microglia. $A-D$, Immunoreactivity of $P 2 Y_{12} R$ protein was detected by a specific antibody for $P 2 Y_{12} R$ in the dorsal spinal cord $7(\boldsymbol{A}, \boldsymbol{B})$ and $14(\boldsymbol{C}, \boldsymbol{D})$ days after nerve injury. Scale bar, $100 \mu \mathrm{m} . \boldsymbol{E}-\boldsymbol{J}$ Double-immunofluorescence labeling of $P 2 Y_{12} R$ with $0 X-42$ (a marker of microglia), GFAP (a marker of astrocytes), and MAP2 (a marker of neurons). Scale bar, $10 \mu \mathrm{m}$.

$\mathrm{P} 2 \mathrm{Y}_{12} \mathrm{R}$ blocking agents induced a relieving effect on existing tactile allodynia

We then examined whether pharmacological blockade of $\mathrm{P} 2 \mathrm{Y}_{12} \mathrm{R}$ could also be effective in treating existing tactile allodynia. On day 7 after nerve injury, the decreased PWT $(p<0.05 ; 12.25 \pm$ $0.73 \mathrm{~g}$ on the contralateral side, $3.61 \pm 0.26 \mathrm{~g}$ on the ipsilateral side) was not changed by intrathecal vehicle administration over a $6 \mathrm{~h}$ period. In contrast, nerve-injured rats intrathecally administered AR-C69931MX on day 7 showed a significant recovery of this decreased PWT from $2 \mathrm{~h}$ after the injection, in a dosedependent manner $(p<0.05)$ (Fig. 5A). AR-C69931MX also produced a recovery of this decreased PWT $(p<0.05 ; 13.46 \pm$ 

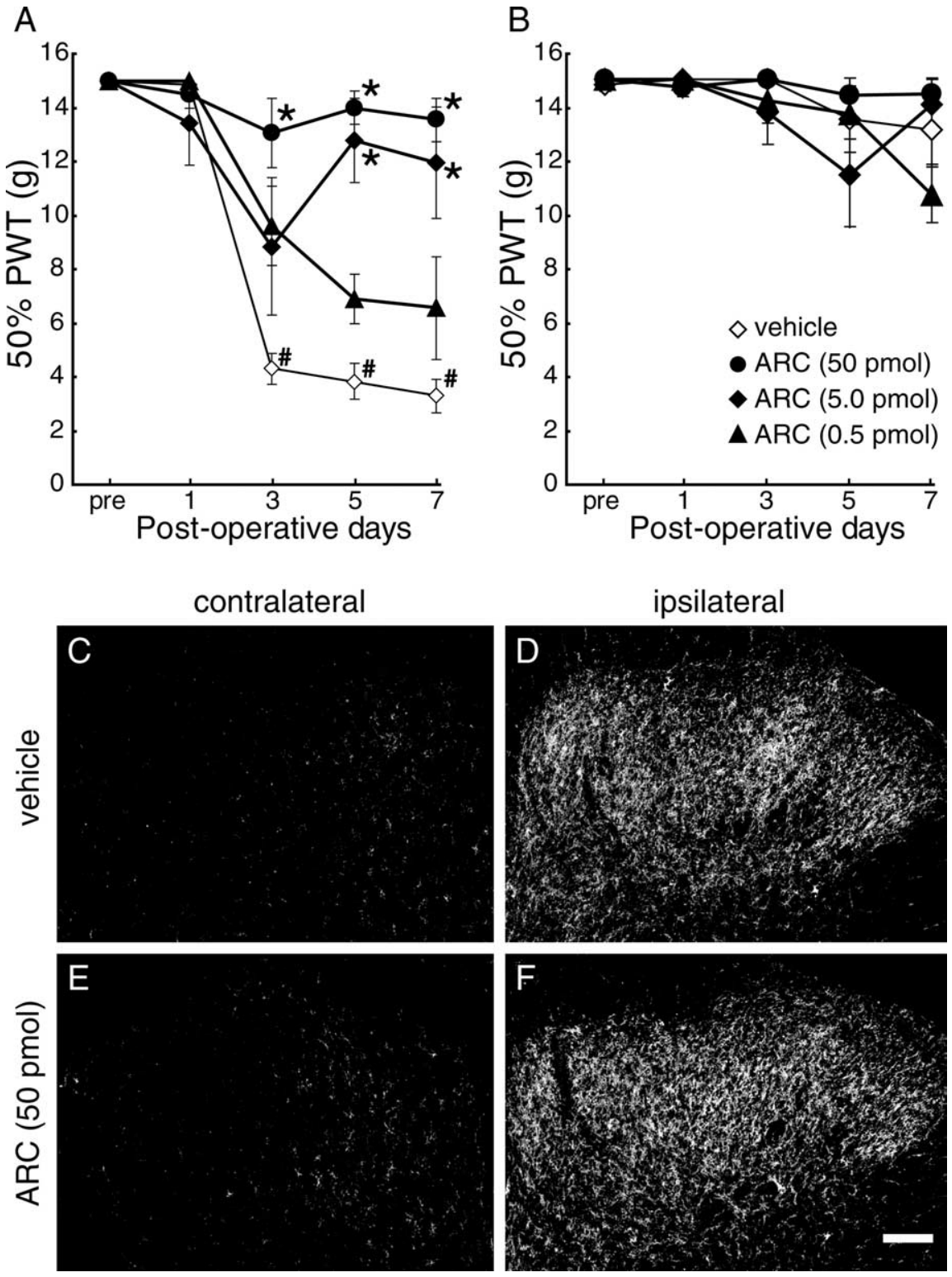

Figure 3. Inhibition of $P 2 Y_{12} R$ prevented the development of tactile allodynia. $\boldsymbol{A}$, The PWT of the ipsilateral hindpaw in response to tactile stimulation in rats were examined before nerve injury and $1,3,5$, and $7 \mathrm{~d}$ after nerve injury. Rats were subjected to intrathecal administration of AR-C69931MX (ARC) at several doses ( $n=5$ each) or vehicle $(n=7)$, twice a day, after peripheral nerve injury. $\boldsymbol{B}$, PWTs were measured in the contralateral hindpaws. Each data point represents the mean \pm SEM of PWT ( ${ }^{*} p<0.05$ vs vehicle group; ${ }^{*} p<0.05$ vs premeasurement by multiple comparison by Tukey's test after a repeatedmeasure two-way ANOVA). $\mathbf{C}-\boldsymbol{F}$, L5 spinal cord segment from $7 \mathrm{~d}$ postoperative rats that received intrathecal injections of vehicle (PBS; $\boldsymbol{C}, \boldsymbol{D})$ or AR-C69931MX (50 pmol; $\boldsymbol{E}, \boldsymbol{F}$ ) twice daily were subjected to immunohistochemistry using anti-0X-42 antibody. Scale bar, $100 \mu \mathrm{m}$.

$0.68 \mathrm{~g}$ on the contralateral side, $3.34 \pm 0.27 \mathrm{~g}$ on the ipsilateral side) on day $14(p<0.05)$ (Fig. $5 C)$. To test for the involvement of other receptors that are antagonized by AR-C69931MX, P2 $\mathrm{Y}_{13}$, and G-protein-coupled receptor 17 (GPR17) (Abbracchio et al., 2006; Ciana et al., 2006; von Kugelgen, 2006), we also tested a selective $\mathrm{P}_{2} \mathrm{Y}_{13}$ receptor antagonist, MRS2211 (500 pmol), and MRS2179 (50 pmol), which works as an antagonist for GPR17 (also as $\mathrm{P}_{2} \mathrm{Y}_{1}$ but not for $\mathrm{P}_{2} \mathrm{Y}_{12}$ ) with high affinity $\left(\mathrm{IC}_{50}\right.$ of $0.18 \mathrm{pM}$ to rat GPR17) (Ciana et al., 2006). These two antagonists failed to produce any effect on the decrease in PWT (Fig. 5B). To further investigate the relieving effect resulting from $\mathrm{P} 2 \mathrm{Y}_{12} \mathrm{R}$ inhibition in a more clinically relevant paradigm, we examined the effect of the peripherally active $\mathrm{P} 2 \mathrm{Y}_{12} \mathrm{R}$ blocker clopidogrel. After a single oral administration of clopidogrel $(1,10$, or $25 \mathrm{mg} / \mathrm{kg}$ ) to nerve-injured rats on day 7 , the PWT $(p<0.05 ; 12.24 \pm 0.59 \mathrm{~g}$ on the contralateral side, $2.92 \pm 0.21 \mathrm{~g}$ on the ipsilateral side) was increased (Fig. 6), and statistically significant differences were observed $3 \mathrm{~h}$ (1, 10, or $25 \mathrm{mg} / \mathrm{kg}), 4 \mathrm{~h}$ (25 $\mathrm{mg} / \mathrm{kg})$, and $6 \mathrm{~h}(25 \mathrm{mg} / \mathrm{kg})$ after the administration of clopidogrel ( $p<0.05$, ipsilateral PWT compared with the vehicletreated group), whereas vehicle-treatment did not produce any effect.

\section{Discussion}

In the present study, we provide the first evidence that activation of $\mathrm{P} 2 \mathrm{Y}_{12}$ Rs in spinal microglia is critical for the pathogenesis of neuropathic allodynia, a major behavioral consequence of nerve injury, using molecular, immunohistochemical, pharmacological, and genetic approaches. Our data from real-time PCR and in situ hybridization analyses show that $\mathrm{P} 2 \mathrm{Y}_{12} \mathrm{R}$ gene expression is increased in the ipsilateral spinal cord after nerve injury, expression of which in the dorsal horn is highly restricted to microglia. The numbers of microglia were also increased in the ipsilateral spinal cord. Because there are some consistencies between the fold increase in the amount of mRNA and the number of microglia, the main reason for the $\mathrm{P} 2 \mathrm{Y}_{12} \mathrm{R}$ mRNA upregulation in the ipsilateral spinal cord tissue is considered to result from the increased numbers of microglia. However, the possibility of transcriptional upregulation of $\mathrm{P} 2 \mathrm{Y}_{12} \mathrm{R}$ in individual activated microglia may also be expected, because our results showed that the fold increase of mRNA was higher than the increase in the number of $\mathrm{P} 2 \mathrm{Y}_{12} \mathrm{R}$ mRNApositive cells. The increased expression of spinal $\mathrm{P} 2 \mathrm{Y}_{12} \mathrm{R}$ after nerve injury is strongly supported by our data showing an increase in the immunofluorescence for $\mathrm{P} 2 \mathrm{Y}_{12} \mathrm{R}$ protein after nerve injury and its specific localization in spinal microglia. The $\mathrm{P} 2 \mathrm{Y}_{12} \mathrm{R}$ immunofluorescence in activated microglia persisted for at least $14 \mathrm{~d}$ after nerve injury, although, after day 7, the level of $\mathrm{P} 2 \mathrm{Y}_{12} \mathrm{R}$ mRNA began to gradually return to the basal level. However, a recent study reported a rapid downregulation of $\mathrm{P} 2 \mathrm{Y}_{12} \mathrm{R}$ protein expression in microglia in hippocampal slice cultures after tissue damage and in the striatum in vivo after treatment with lipopolysaccharide (LPS), a major constituent of the outer membrane of Gram-negative bacteria (Haynes et al., 2006). The exact reason for the inconsistency in the regulation of $\mathrm{P} 2 \mathrm{Y}_{12} \mathrm{R}$ expression in activated microglia remains unclear, but it might be explained by differences between different regions of the CNS (spinal cord vs hippocampus and striatum) and/or in the experimental methods for activation of microglia (peripheral nerve injury vs LPS and slicing the brain tissue). Consistently with our results, microglial $\mathrm{P}_{2} \mathrm{Y}_{12} \mathrm{R}$ upregu- 

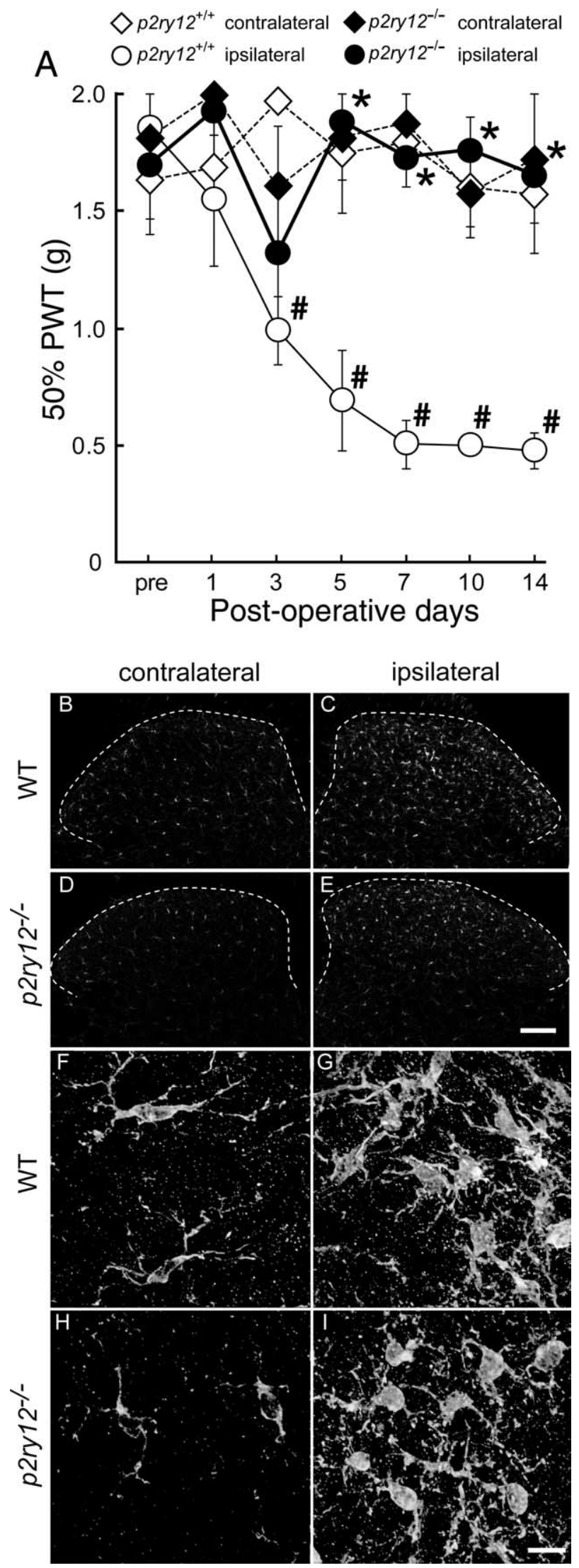

Figure 4. Deletion of $P 2 r y 12$ attenuated the development of tactile allodynia. $A$, PWT was measured in wild-type and $P 2 r y 12^{-/-}$mice before and after $L 5$ spinal nerve transection. Each data point represents the mean \pm SEM of PWT (in grams) of four animals from each group ( ${ }^{*} p<0.05$ vs p2ry $12^{+/+}$group; $p<0.05$ vs premeasurement by multiple comparison by Tukey's test after a repeated-measure two-way ANOVA). B-E, L5 spinal cord segments from $14 \mathrm{~d}$ lation is also observed in the facial nucleus after injury to the peripheral facial motor nerve (Sasaki et al., 2003). Therefore, the results of the present study suggest that activated microglia may upregulate the expression of $\mathrm{P} 2 \mathrm{Y}_{12} \mathrm{R}$, at both mRNA and protein levels, in response to peripheral nerve injury.

Our present behavioral study demonstrated that blocking spinal $\mathrm{P} 2 \mathrm{Y}_{12} \mathrm{R}$ chronically, by means of repeated intrathecal administration of AR-C69931MX, prevented the development of nerve injury-induced tactile allodynia. The functional relevance of $\mathrm{P} 2 \mathrm{Y}_{12} \mathrm{R}$ in neuropathic allodynia is substantially supported by our data obtained from a behavioral analysis of $\mathrm{P} 2 \mathrm{Y}_{12} \mathrm{R}$-deficient mice; $P 2 r y 12^{-/-}$mice failed to show tactile allodynia after nerve injury and showed no deficit in basal sensitivity to mechanical stimuli and motor function. These results, together with the highly restricted localization of $\mathrm{P} 2 \mathrm{Y}_{12} \mathrm{R}$ to microglia, indicate that the $\mathrm{P} 2 \mathrm{Y}_{12} \mathrm{R}$ activation in spinal cord microglia may be responsible for the expression of neuropathic allodynia after nerve injury. Thus, $\mathrm{P} 2 \mathrm{Y}_{12} \mathrm{R}$-mediated microglial functions (for example, morphological changes, chemotaxis, and process movement) are considered to be required for the development of neuropathic allodynia. However, P2ry $12^{-/-}$mice were indistinguishable from wild-type mice with regard to the number and morphology of activated microglia in the ipsilateral spinal dorsal horn. Therefore, $\mathrm{P} 2 \mathrm{Y}_{12}$ Rs might not have a major role in the morphological changes of spinal microglia triggered by peripheral nerve injury.

We thus considered the possibility that $\mathrm{P} 2 \mathrm{Y}_{12}$ Rs may participate in the functions of already activated microglia. This notion is supported by our data showing that (1) neither the pharmacological blockade of $\mathrm{P} 2 \mathrm{Y}_{12}$ Rs nor the genetic ablation of $\mathrm{P} 2 \mathrm{Y}_{12} \mathrm{R}$ affected the mechanical sensitivity on the contralateral side in nerve-injured animals or that in non-injured animals whose dorsal horns have normal resting type microglia, and (2) the upregulation of $\mathrm{P} 2 \mathrm{Y}_{12} \mathrm{R}$ occurs in activated microglia in the dorsal horn after nerve injury. In the present study, we demonstrated that nerve injury-induced tactile allodynia was reversed by a single intrathecal administration of AR-C69931MX, implying that an ongoing activity of $\mathrm{P} 2 \mathrm{Y}_{12} \mathrm{R}$ in spinal microglia also contributes to emerging tactile allodynia after nerve injury. Notably, we also demonstrated a reversing effect of a orally administered clopidogrel (Emmons and Taylor, 2007), a well known antithrombotic compound targeting $\mathrm{P} 2 \mathrm{Y}_{12} \mathrm{R}$ in platelets with safety profiles from an extensive clinical program (Savi and Herbert, 2005), on existing tactile allodynia. It has been reported that the antagonistic effect of clopidogrel on $\mathrm{P} 2 \mathrm{Y}_{12} \mathrm{R}$ is dependent on its active metabolite through hepatic metabolism, and $10 \mathrm{mg} / \mathrm{kg}$ oral clopidogrel induced $\sim 90 \%$ inhibition of ex vivo platelet aggregation, and a transfer of the clopidogrel or its metabolite across the blood-brain barrier was also observed (Herbert et al., 1993). Because we observed a significant effect of clopidogrel with 10 $\mathrm{mg} / \mathrm{kg}$ oral administration and a higher dose $(25 \mathrm{mg} / \mathrm{kg})$ achieved a rather longer-lasting relieving effect on existing tactile allodynia, transfer of active metabolite of clopidogrel from plasma to the spinal cord parenchyma might be limited. Furthermore, the slow onset of the anti-allodynic effects may be attributable in part to such pharmacokinetics. It should be noted that this analgesia may be an off-target effect of clopidogrel, because the clinical

\section{$\leftarrow$}

postoperative mice were subjected to immunohistochemistry using anti-lba1 antibody. Dotted lines trace the outline of the dorsal horn. Scale bar, $100 \mu \mathrm{m}$. F-I, High-magnification images constructed from a series of $z$-stack images using the deconvolution technique. Scale bar, $10 \mu \mathrm{m}$. 

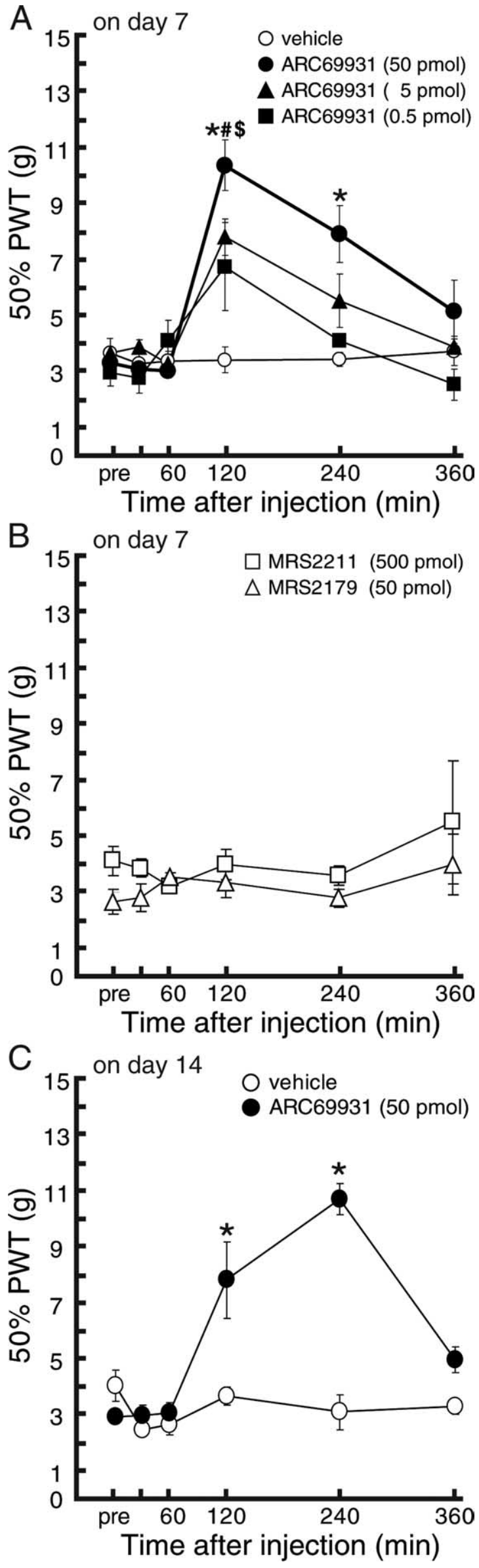

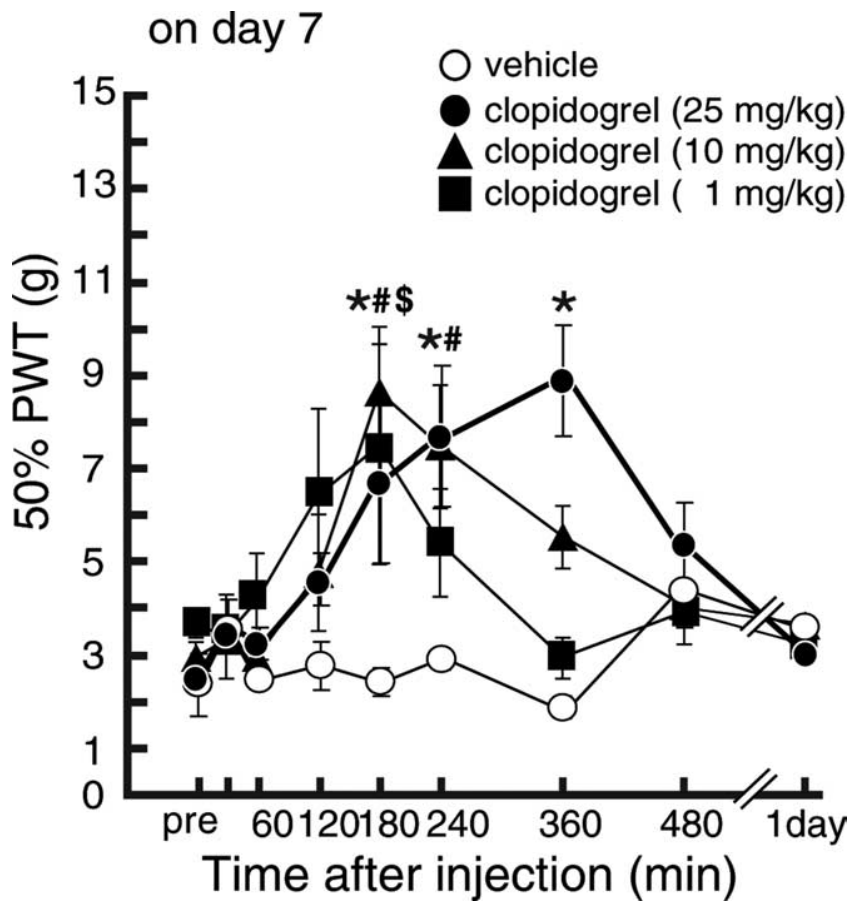

Figure 6. Relieving effects of systemically administered clopidogrel in rats with tactile allodynia. Seven day postoperative rats showing strong tactile allodynia were subjected to verification of the analgesic effect induced by clopidgrel. Systemically administered clopidogrel (1, 10 , and $25 \mathrm{mg} / \mathrm{kg} ; n=4,5$, and 6 ), but not vehicle $(n=3)$, also showed an analgesic effect in rats with tactile allodynia $7 \mathrm{~d}$ after peripheral nerve injury. Each data point represents the mean \pm SEM of PWT ( ${ }^{5, \#, *} p<0.05 ; 1,10$, and $25 \mathrm{mg} / \mathrm{kg}$-treated groups vs vehicle group by multiple comparison by Tukey's test after a repeated-measure two-way ANOVA).

target of this compound is $\mathrm{P} 2 \mathrm{Y}_{12} \mathrm{R}$ in platelets. These behavioral data thus suggest that activation of $\mathrm{P} 2 \mathrm{Y}_{12} \mathrm{R}$, which is upregulated in spinal microglia, may be crucial for the maintenance of neuropathic pain after nerve injury, in addition to the role in its development.

The mechanism(s) underlying microglial $\mathrm{P}_{2} \mathrm{Y}_{12} \mathrm{R}$-mediated neuropathic pain regulation remains to be determined. Accumulating evidence has indicated that the development and maintenance of neuropathic pain are also regulated by activities of other microglial molecules [for example, $\mathrm{P}_{2} \mathrm{X}_{4} \mathrm{R}$ (Tsuda et al., 2003), chemokine receptors (Zhang et al., 2007; Zhuang et al., 2007), Toll-like receptors (Tanga et al., 2005; Kim et al., 2007), mitogenactivated protein kinases (Jin et al., 2003; Zhuang et al., 2005), Src-family kinases (Katsura et al., 2006), and cathepsin S (Clark et al., 2007)]. It is possible that $P 2 Y_{12} R$ may interact with these molecules in activated spinal microglia and that this interaction may cause neuropathic pain. Indeed, we recently demonstrated that ATP-induced chemotaxis of microglial cells requires both $\mathrm{P} 2 \mathrm{Y}_{12} \mathrm{R}$ and $\mathrm{P} 2 \mathrm{X}_{4} \mathrm{R}$, an important microglial molecule for neuro-

Figure 5. Relieving effects of AR-C69931MX in rats with tactile allodynia. A, B, Seven day postoperative rats showing strong tactile allodynia were subjected to verification of the analgesic effect induced by intrathecal administration of drugs. Vehicle $(n=6), \operatorname{AR}-\operatorname{C69931MX}(0.5$, 5 , and $50 \mathrm{pmol} ; n=5-7$ ), MRS2211 (500 pmol; $n=4)$, or MRS2179 (50 pmol; $n=3$ ) was injected intrathecally, and PWT was measured. C, Fourteen day postoperative rats showing strong tactile allodynia were subjected to verification of the analgesic effect induced by $P 2 Y_{12}$ blocking agents. Vehicle $(n=3)$ or AR-C69931MX ( $50 \mathrm{pmol} ; n=5)$ was injected intrathecally, and PWT was measured. Each data point represents the mean \pm SEM of PWT $\left({ }^{5, \#, *} p<0.05\right.$; $0.5,5$, and $50 \mathrm{pmol}$-treated groups vs the vehicle group by multiple comparison by Tukey's test after a repeated-measure two-way ANOVA). 
pathic pain (Ohsawa et al., 2007), although its role in neuropathic pain remains unknown. Several lines of evidence have indicated that $\mathrm{P} 2 \mathrm{Y}_{12} \mathrm{R}$ is implicated in the motility of microglial cell bodies and processes (Honda et al., 2001; Davalos et al., 2005; Haynes et al., 2006; Wu et al., 2007). It is thus possible that $\mathrm{P} 2 \mathrm{Y}_{12} \mathrm{R}$ activity in microglia may influence the abilities of microglia to extend the tips of their branched processes toward neighboring pain transmission neurons, which may in turn affect microglia-neuron communications. Future studies focusing on the physical contact between microglial processes and other cells, using electron microscopy, will be important to advance our understanding of the mechanisms by which spinal microglia control nerve injuryinduced neuropathic pain.

In summary, the present study demonstrated that $\mathrm{P} 2 \mathrm{Y}_{12} \mathrm{R}$ expression is upregulated at both mRNA and protein levels in the ipsilateral spinal cord after nerve injury and that this expression is highly restricted to microglia. Intrathecal administration of the P2 ${ }_{12} \mathrm{R}$ antagonist AR-C69931MX prevented the development of tactile allodynia, and $P 2 r y 12^{-1-}$ mice displayed impaired tactile allodynia after nerve injury. We also found that a single intrathecal administration of AR-C69931MX or oral administration of clopidogrel to nerve-injured rats produced a striking alleviation of existing tactile allodynia. These results suggest that activation of $\mathrm{P} 2 \mathrm{Y}_{12}$ Rs in spinal microglia may be a critical event in the development and maintenance of neuropathic pain and that blocking microglial $\mathrm{P} 2 \mathrm{Y}_{12}$ Rs might represent a therapeutic strategy for treating neuropathic pain.

\section{References}

Abbracchio MP, Burnstock G, Boeynaems JM, Barnard EA, Boyer JL, Kennedy C, Knight GE, Fumagalli M, Gachet C, Jacobson KA, Weisman GA (2006) International Union of Pharmacology LVIII: update on the P2Y G protein-coupled nucleotide receptors: from molecular mechanisms and pathophysiology to therapy. Pharmacol Rev 58:281-341.

Burnstock G (2006) Purinergic P2 receptors as targets for novel analgesics. Pharmacol Ther 110:433-454.

Chaplan SR, Bach FW, Pogrel JW, Chung JM, Yaksh TL (1994) Quantitative assessment of tactile allodynia in the rat paw. J Neurosci Methods 53:55-63.

Ciana P, Fumagalli M, Trincavelli ML, Verderio C, Rosa P, Lecca D, Ferrario S, Parravicini C, Capra V, Gelosa P, Guerrini U, Belcredito S, Cimino M, Sironi L, Tremoli E, Rovati GE, Martini C, Abbracchio MP (2006) The orphan receptor GPR17 identified as a new dual uracil nucleotides/ cysteinyl-leukotrienes receptor. EMBO J 25:4615-4627.

Clark AK, Gentry C, Bradbury EJ, McMahon SB, Malcangio M (2007) Role of spinal microglia in rat models of peripheral nerve injury and inflammation. Eur J Pain 11:223-230.

Coull JA, Beggs S, Boudreau D, Boivin D, Tsuda M, Inoue K, Gravel C, Salter MW, De Koninck Y (2005) BDNF from microglia causes the shift in neuronal anion gradient underlying neuropathic pain. Nature 438:1017-1021.

Davalos D, Grutzendler J, Yang G, Kim JV, Zuo Y, Jung S, Littman DR, Dustin ML, Gan WB (2005) ATP mediates rapid microglial response to local brain injury in vivo. Nat Neurosci 8:752-758.

Di Virgilio F, Chiozzi P, Ferrari D, Falzoni S, Sanz JM, Morelli A, Torboli M, Bolognesi G, Baricordi OR (2001) Nucleotide receptors: an emerging family of regulatory molecules in blood cells. Blood 97:587-600.

Emmons KL, Taylor NR (2007) Contemporary issues in clopidogrel therapy: new evidence shaping clinical practice. Pharmacotherapy 27:553-563.

Hashimoto M, Sugidachi A, Isobe T, Niitsu Y, Ogawa T, Jakubowski JA, Asai $\mathrm{F}$ (2007) The influence of $\mathrm{P}_{2} \mathrm{Y}_{12}$ receptor deficiency on the platelet inhibitory activities of prasugrel in a mouse model: evidence for specific inhibition of $\mathrm{P}_{2} \mathrm{Y}_{12}$ receptors by prasugrel. Biochem Pharmacol 74:1003-1009.

Haynes SE, Hollopeter G, Yang G, Kurpius D, Dailey ME, Gan WB, Julius D
(2006) The $\mathrm{P}_{2} \mathrm{Y}_{12}$ receptor regulates microglial activation by extracellular nucleotides. Nat Neurosci 9:1512-1519.

Herbert JM, Frehel D, Vallee E, Kieffer G, Gouy D, Berger Y, Necciari J, Defreyn G, Maffrand JP (1993) Clopidogrel, a novel antiplatelet and antithrombotic agent. Cardiovasc Drug Rev 11:180-198.

Honda S, Sasaki Y, Ohsawa K, Imai Y, Nakamura Y, Inoue K, Kohsaka S (2001) Extracellular ATP or ADP induce chemotaxis of cultured microglia through $\mathrm{G}_{\mathrm{i} / \mathrm{o}}$-coupled P2Y receptors. J Neurosci 21:1975-1982.

Ingall AH, Dixon J, Bailey A, Coombs ME, Cox D, McInally JI, Hunt SF, Kindon ND, Teobald BJ, Willis PA, Humphries RG, Leff P, Clegg JA, Smith JA, Tomlinson W (1999) Antagonists of the platelet P2T receptor: a novel approach to antithrombotic therapy. J Med Chem 42:213-220.

Inoue $\mathrm{K}$ (2006) The function of microglia through purinergic receptors: neuropathic pain and cytokine release. Pharmacol Ther 109:210-226.

Jin SX, Zhuang ZY, Woolf CJ, Ji RR (2003) p38 mitogen-activated protein kinase is activated after a spinal nerve ligation in spinal cord microglia and dorsal root ganglion neurons and contributes to the generation of neuropathic pain. J Neurosci 23:4017-4022.

Katsura H, Obata K, Mizushima T, Sakurai J, Kobayashi K, Yamanaka H, Dai Y, Fukuoka T, Sakagami M, Noguchi K (2006) Activation of Src-family kinases in spinal microglia contributes to mechanical hypersensitivity after nerve injury. J Neurosci 26:8680-8690.

Kim D, Kim MA, Cho IH, Kim MS, Lee S, Jo EK, Choi SY, Park K, Kim JS, Akira S, Na HS, Oh SB, Lee SJ (2007) A critical role of toll-like receptor 2 in nerve injury-induced spinal cord glial cell activation and pain hypersensitivity. J Biol Chem 282:14975-14983.

Koizumi S, Shigemoto-Mogami Y, Nasu-Tada K, Shinozaki Y, Ohsawa K, Tsuda M, Joshi BV, Jacobson KA, Kohsaka S, Inoue K (2007) UDP acting at $\mathrm{P}_{2} \mathrm{Y}_{6}$ receptors is a mediator of microglial phagocytosis. Nature 446:1091-1095.

Kurpius D, Nolley EP, Dailey ME (2007) Purines induce directed migration and rapid homing of microglia to injured pyramidal neurons in developing hippocampus. Glia 55:873-884.

Marchand F, Perretti M, McMahon SB (2005) Role of the immune system in chronic pain. Nat Rev Neurosci 6:521-532.

Ohsawa K, Irino Y, Nakamura Y, Akazawa C, Inoue K, Kohsaka S (2007) Involvement of $\mathrm{P}_{2} \mathrm{X}_{4}$ and $\mathrm{P}_{2} \mathrm{Y}_{12}$ receptors in ATP-induced microglial chemotaxis. Glia 55:604-616.

Sasaki Y, Hoshi M, Akazawa C, Nakamura Y, Tsuzuki H, Inoue K, Kohsaka S (2003) Selective expression of Gi/o-coupled ATP receptor $\mathrm{P}_{2} \mathrm{Y}_{12}$ in microglia in rat brain. Glia 44:242-250.

Savi P, Herbert JM (2005) Clopidogrel and ticlopidine: P2Y $_{12}$ adenosine diphosphate-receptor antagonists for the prevention of atherothrombosis. Semin Thromb Hemost 31:174-183.

Tanga FY, Nutile-McMenemy N, DeLeo JA (2005) The CNS role of Tolllike receptor 4 in innate neuroimmunity and painful neuropathy. Proc Natl Acad Sci USA 102:5856-5861.

Tsuda M, Shigemoto-Mogami Y, Koizumi S, Mizokoshi A, Kohsaka S, Salter MW, Inoue K (2003) P2X $\mathrm{X}_{4}$ receptors induced in spinal microglia gate tactile allodynia after nerve injury. Nature 424:778-783.

Tsuda M, Inoue K, Salter MW (2005) Neuropathic pain and spinal microglia: a big problem from molecules in "small" glia. Trends Neurosci 28:101-107.

von Kugelgen I (2006) Pharmacological profiles of cloned mammalian P2Yreceptor subtypes. Pharmacol Ther 110:415-432.

Watkins LR, Maier SF (2003) Glia: a novel drug discovery target for clinical pain. Nat Rev Drug Discov 2:973-985.

Wu LJ, Vadakkan KI, Zhuo M (2007) ATP-induced chemotaxis of microglial processes requires $\mathrm{P} 2 \mathrm{Y}$ receptor-activated initiation of outward potassium currents. Glia 55:810-821.

Zhang J, Shi XQ, Echeverry S, Mogil JS, De Koninck Y, Rivest S (2007) Expression of CCR2 in both resident and bone marrow-derived microglia plays a critical role in neuropathic pain. J Neurosci 27:12396-12406.

Zhuang ZY, Gerner P, Woolf CJ, Ji RR (2005) ERK is sequentially activated in neurons, microglia, and astrocytes by spinal nerve ligation and contributes to mechanical allodynia in this neuropathic pain model. Pain 114:149-159.

Zhuang ZY, Kawasaki Y, Tan PH, Wen YR, Huang J, Ji RR (2007) Role of the CX3CR1/p38 MAPK pathway in spinal microglia for the development of neuropathic pain following nerve injury-induced cleavage of fractalkine. Brain Behav Immun 21:642-651. 